\title{
Induction of systemic inflammation by hyaluronan and hsp70 in women with pre-eclampsia
}

\author{
Mariana Romão-Veiga ${ }^{\mathrm{a}, *}$, Mariana Leticia Matias ${ }^{\mathrm{b}}$, Vanessa Rocha Ribeiro ${ }^{\mathrm{b}}$, \\ Priscila Rezeck Nunes ${ }^{\mathrm{b}}$, Vera Therezinha M. Borges ${ }^{\mathrm{b}}$, José Carlos Peraçoli ${ }^{\mathrm{b}}$, \\ Maria Terezinha S. Peraçoli ${ }^{\mathrm{a}}$ \\ a Department of Microbiology and Immunology, Institute of Biosciences, Botucatu, São Paulo State University - UNESP, Botucatu, São Paulo, Brazil \\ ${ }^{\mathbf{b}}$ Department of Gynaecology and Obstetrics, Botucatu Medical School, Botucatu, São Paulo State University - UNESP, Botucatu, São Paulo, Brazil
}

\section{A R T I C L E I N F O}

\section{Keywords:}

Cytokines

DAMPs

Inflammasomes

Monocytes

Pre-eclampsia

\begin{abstract}
A B S T R A C T
Pre-eclampsia (PE) is a human pregnancy syndrome with abnormal activation of the innate immune response. The study evaluated the involvement of molecular structures called damage-associated molecular patterns (DAMPs), such as hyaluronan (HA) and heat shock proteins (Hsp) on NLRP1 and NLRP3 inflammasomes activation in peripheral blood monocytes. Twenty pre-eclamptic women, 20 normotensive pregnant women (NT) and 20 non-pregnant women (NP) were studied. Enzyme immunoassay was employed for the determination of HA, Hsp70 and High mobility group Box 1 (HMGB1) in plasma, as well as for the detection of Interleukin-1ß (IL$1 \beta)$, IL-18 and tumor necrosis factor alpha (TNF- $\alpha$ ) in the supernatant of monocytes cultured with or without HA and Hsp70. The inflammasomes induction was evaluated by the quantification of mRNA for NLRP1, NLRP3, caspase-1, IL-1 $\beta$, IL-18, HMGB1 and TNF- $\alpha$ by qPCR in monocyte culture. The results showed significantly higher plasma levels of HA, Hsp70 and HMGB1 in pre-eclamptic women than in NT and NP women. Monocytes from women with PE showed endogenous activation of NLRP1 and NLRP3 inflammasomes, and expressed high amounts of IL-1 $\beta$, IL-18, HMGB1 and TNF- $\alpha$. The stimulation of monocytes with HA increased the gene expression of NLRP1, NLRP3, caspase-1, TNF- $\alpha$, IL-1 $\beta$, HMGB1 and IL-18 and the production of IL- $1 \beta$ in preeclamptic women. Monocytes cultured with Hsp70 produced elevated levels of IL-1 $\beta$ and TNF- $\alpha$ through a mechanism independent of inflammasomes activation. These results suggest the participation of these DAMPs in the systemic inflammatory response that is characteristic of PE.
\end{abstract}

\section{Introduction}

Maternal immune adaptation is required for pregnancy involving innate and adaptive immunity, to permit normal development and growth of the fetal semi-graft [1]. A specific syndrome called preeclampsia (PE) can be present in $2-10 \%$ of human pregnancies [2], and is the leading cause of mortality, morbidity and premature labor. This pathology is primarily identified by hypertension and proteinuria from 20 weeks of gestation [3] or by hypertension associated with maternal neurologic or hematologic complications, kidney failure, liver involvement or fetal growth restriction $[4,5]$.

PE shows intense inflammatory response that seems to be related to molecules capable of inducing inflammation, which are called damage- associated molecular patterns (DAMPs) [6]. DAMPs are represented by molecules such as uric acid [7], reactive oxygen species, heat shock proteins (Hsps) [8], proteins released from cells such as HMGB1 [9] and products released from the extracellular matrix such as hyaluronan $[10,11]$. Plasma concentration of Hsp70 was significantly higher in pregnant women with early-onset PE than in the late-onset PE [12]. The release of Hsp70 by monocytes/macrophages acts as a "danger signal" stimulating TNF- $\alpha$, IL- 6 and IL-8 production by the human monocytic cell line THP-1 [13].

High mobility group box 1 (HMGB1) is considered as a "danger signal", acting as a pro-inflammatory mediator [14]. The release of HMGB1 in endotoxemia is dependent on activation of the NLRP3 inflammasome [15]. Plasma level of this protein is increased in women

\footnotetext{
Abbreviations: cDNA, complementary DNA; DAMPs, damage-associated molecular patterns; EDTA, ethylenediamine tetra acetic acid; ELISA, enzyme-linked immunosorbent assay;

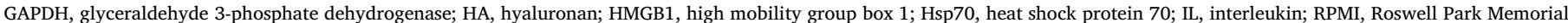

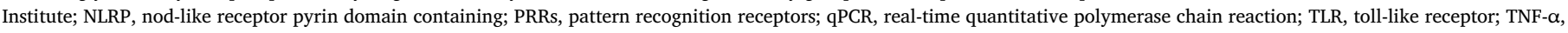
tumor necrosis factor alpha

* Corresponding author at: Department of Microbiology and Immunology, Institute of Biosciences, Rubiao Junior s/n, UNESP, Botucatu, Sao Paulo CEP 18618-691, Brazil.

E-mail address: mromao@ibb.unesp.br (M. Romão-Veiga).
} 
with PE compared to normotensive pregnant women [16] and may contribute to the development of the inflammatory response in women with PE [17].

Hyaluronan (HA) is a glycosaminoglycan of the extracellular matrix, which undergoes rapid degradation in inflammatory environments, resulting in the accumulation of low molecular weight fragments [10]. These fragments activate the pro-inflammatory response via Toll-like receptors (TLR) 2 and TLR4, and can also activate the NLRP3 inflammasome acting as a DAMP [18]. Elevated plasma levels of HA are described in women with PE $[19,20]$.

DAMPs exert their inflammatory effect by interacting with the main pattern recognition receptors (PRRs) such as Toll-like (TLRs) and NLR receptors expressed on innate immune cells involved in the inflammatory response [21]. Activation of NLR receptors by DAMPs induces the cleavage of the inactive form of caspase- 1 that becomes biologically active $[22,23]$. Caspase- 1 is responsible for cleaving pro-IL$1 \beta$ and pro-IL-18 to the biologically active forms IL- $1 \beta$ and IL-18, which are subsequently secreted into the extracellular medium [24]. Since NLR3 inflammasome may be activated by DAMPs in monocytes from women with PE, the present study aimed to evaluate the involvement of hyaluronan (HA) and Hsp70 in NLRP1 and NLRP3 inflamassomes activation in monocytes from women with $\mathrm{PE}$, as well as normotensive pregnant and non-pregnant women.

\section{Materials and methods}

\subsection{Subjects}

The study included 40 pregnant women admitted to the Obstetric Unit of Botucatu Medical School, Botucatu, SP, Brazil. Twenty women, without preexistent hypertension or obstetric and medical complications, were diagnosed with PE. A group of 20 pregnant women with an uncomplicated pregnancy matched for gestational age with the preeclamptic group were recruited as controls. Gestational age was confirmed by early ( $<12$ weeks gestation) ultrasound examination. Twenty healthy non-pregnant women, volunteer donors of the Blood Bank from the Hemocenter of the Botucatu Medical School were included to compare the immunological parameters between groups. Proteinuria was measured in 24-h urine by the Technicon RAXT automation system, a colorimetric method and uric acid was determined by uric acid enzymatic Trinder (Biotrol Diagnostic). Exclusion criteria included prior pre-eclampsia, illicit drug use, multiple gestation and preexisting medical conditions such as renal disease, diabetes and chronic hypertension. The Ethics Committee of the Botucatu Medical School approved the study (Protocol $n^{\circ}$ 349.847) and all women signed a written informed consent. Parents or guardians have signed for women with age below 18 years old.

\subsection{Blood sampling}

Ten milliliters of blood from all women was collected into plastic tubes containing 5\% EDTA and centrifuged for $10 \mathrm{~min}$ at $1200 \mathrm{~g}$. The plasma was collected and stored in aliquots at $-80^{\circ} \mathrm{C}$ until analyses.

\subsection{Monocyte cultures}

After plasma separation, density gradient centrifugation method was used to isolate peripheral blood mononuclear cells (PBMCs) on Ficoll-Paque Premium [density (d) =1.077] (GE Healthcare BioSciences, Uppsala, Sweden) as previously described [25]. Cell viability was $>95 \%$ in all experiments as determined by $0.2 \%$ Trypan Blue dye exclusion. Neutral red dye $(0.02 \%)$ was used to count monocytes to final concentration of $5 \times 10^{5}$ monocytes $/ \mathrm{mL}$ in complete medium and distributed ( $1 \mathrm{~mL} /$ well) in 24-well flat-bottomed plates (NalgeNunc, Rochester, NY, USA). After $2 \mathrm{~h}$ of incubation at $37^{\circ} \mathrm{C}$ in $5 \% \mathrm{CO}_{2}$ atmosphere, each well was rinsed twice with complete medium to remove non-adherent cells. Monocyte culture routinely contained $>90 \%$ monocytes as determined by morphology and staining examination [26]. These cells were incubated with or without $100 \mathrm{ng} / \mathrm{mL}$ of low molecular weight hyaluronan (HA) (R\&D Systems, Minneapolis, USA) or $2.5 \mathrm{ng} / \mathrm{mL}$ of Hsp70 (Sigma-Aldrich). The concentrations of HA and Hsp70 were previously standardized employing monocytes from healthy non-pregnant women. To rule out the presence of endotoxin in HA and Hsp70 stimuli preparation, a culture with these stimuli was performed employing polymixin B (PMX-B). The addition of PMX-B to monocyte cultures significantly decreased TNF- $\alpha$ production by LPSstimulated cells, while there was no effect on the cytokine release after $\mathrm{HA}$ and Hsp70 stimulation (data not shown). Culture supernatants were collected and stored at $-80^{\circ} \mathrm{C}$ until cytokines determination.

\subsection{DAMPs and cytokines determination}

Quantification of DAMPs (Hyaluronan and Hsp70) in plasma and TNF- $\alpha$ and IL- $1 \beta$ cytokines in the supernatants of monocytes cultured in the presence or absence of hyaluronan (HA) or Hsp70 were done by specific commercial kits obtained from R\&D Systems. IL-18 was determined in monocytes supernatant using the quantitative ELISA kit (MBL - Medical \& Biological Laboratories, Japan). HMGB1 was quantified in plasma using the IBL kit International - Shino Test (Hamburg, Germany). In the tests, the concentrations of monoclonal and polyclonal antibodies, as well as the specific recombinant cytokines used in standard curves were those recommended by the manufacturer. Assay sensitivity limits were $0.4 \mathrm{ng} / \mathrm{mL}$ hyaluronan, $125 \mathrm{pg} / \mathrm{mL} \mathrm{Hsp} 70$, $0.1 \mathrm{ng} / \mathrm{mL}$ HMGB1, $15.6 \mathrm{pg} / \mathrm{mL}$ TNF- $\alpha, 3.9 \mathrm{pg} / \mathrm{mL} \mathrm{IL}-1 \beta$ and $12.5 \mathrm{pg} /$ mL IL-18.

\subsection{Expression of transcripts related to inflammation}

Monocytes were incubated with or without $100 \mathrm{ng} / \mathrm{mL}$ of HA (R\&D Systems) or $2.5 \mathrm{ng} / \mathrm{mL}$ of Hsp70 (Sigma-Aldrich) for $4 \mathrm{~h}$ and were submitted to gene expression of the genes encoding the proteins NLRP1, NLRP3, caspase-1, HMGB1, IL-1 $\beta$, IL-18 and TNF- $\alpha$. Glibenclamide (Sigma-Aldrich) was added to monocytes cultures from 5 non-pregnant women for $30 \mathrm{~min}$ at concentration of 50 and $200 \mu \mathrm{M}$ before incubating $\mathrm{HA}(100 \mathrm{ng} / \mathrm{mL})$ culture for $4 \mathrm{~h}$ this procedure allowed evaluating the inhibitory effect of glibenclamide on HA activation of NLRP3 inflammasome. Total RNA Purification Kit (NorgenBiotek Corp., Thorold, Canada) was used to extract total mRNA from monocytes according to the manufacturer's protocol. The purity and relative quality of samples, synthesis of complementary DNA (cDNA) and the gene expression of NLRP1, NLRP3, caspase-1, HMGB1, TNF- $\alpha$, IL-1 $\beta$ and IL-18 by real-time quantitative Polymerase Chain Reaction (RT-qPCR) were performed as described by Matias et al. [7]. The primer sequences are shown in Table 1. Differential expression of genes was performed by the data processing method in relation to a standard curve [27]. To relative expression analysis an mRNA sample was select from each group and received 100 as relative value. All other samples received values based on that sample.

\subsection{Statistical analysis}

Nonparametric tests (Mann-Whitney $U$ test or Kruskal-Wallis) were employed to analyze the characteristics of the women and concentration of DAMPs. Cytokine production and gene expression data were evaluated by parametric analysis of variance (ANOVA). Results were evaluated using the statistical program PRISM, (Graph Prism, version 6.01, GraphPad, CA, USA) and statistical significance was accepted at $\mathrm{p}<0.05$. 
Table 1

Primers of inflammasomes proteins, cytokines and GAPDH.

\begin{tabular}{|c|c|c|c|}
\hline Gene & Forward primer $\left(5^{\prime}-3^{\prime}\right)$ & Reverse primer $\left(5^{\prime}-3^{\prime}\right)$ & GenBank \\
\hline NLRP1 & (1728)TCCGGCTCCCATTAGACAGA(1747) & (1810)AGACCCATCCTGGCTCATCT(1791) & NM_033004.3 \\
\hline NLRP3 & (2826)GAGGAAAAGGAAGGCCGACA(2845) & (2917)TGGCTGTTCACCAATCCATGA(2897) & NM_004895.4 \\
\hline CASP1 & (1065)AGACATCCCACAATGGGCTC(1084) & (1172)TGAAAATCGAACCTTGCGGAAA(1151) & NM_033292.3 \\
\hline HMGB1 & (1404)TACGAAAAGGATATTGCTGC(1423) & (1505)СТССТCTTCCTTCTTTTTCTTG(1484) & NM_001313893.1 \\
\hline IL1B & (544)GAGCAACAAGTGGTGTTCTCC(564) & (653)AACACGCAGGACAGGTACAG(634) & NM_000576.2 \\
\hline IL-18 & (438)ACTGTAGAGATAATGCACCCCG(459) & (517)AGTTACAGCCATACCTCTAGGC(496) & NM_001562.3 \\
\hline TNF & (325)GCTGCACTTTGGAGTGATCG(344) & (462)GGGTTTGCTACAACATGGGC(443) & NM_000594.3 \\
\hline GAPDH & (684)CGTGGAAGGACTCATGACCA(703) & (801)GGCAGGGATGATGTTCTGGA(782) & NM_002046.4 \\
\hline
\end{tabular}

Table 2

Clinical and laboratorial characteristics.

\begin{tabular}{|c|c|c|c|c|}
\hline \multicolumn{2}{|c|}{ Characteristics } & $\begin{array}{l}\text { Pregnant women } \\
\text { with pre- } \\
\text { eclampsia } \\
(n=20)\end{array}$ & $\begin{array}{l}\text { Normotensive } \\
\text { pregnant women } \\
(\mathrm{n}=20)\end{array}$ & $\begin{array}{l}\text { Non- } \\
\text { pregnant } \\
\text { women } \\
(\mathrm{n}=20)\end{array}$ \\
\hline \multicolumn{2}{|c|}{ Age (years) } & $25(15-40)$ & $26(14-41)$ & $24(21-40)$ \\
\hline \multirow[t]{2}{*}{ Race } & Caucasian (\%) & 82.3 & 89.6 & 84.0 \\
\hline & $\begin{array}{l}\text { Non- } \\
\text { Caucasian (\%) }\end{array}$ & 17.7 & 10.4 & 16.0 \\
\hline \multicolumn{2}{|c|}{ Gestational age (weeks) } & $34(23-40)$ & $35(24-39)$ & - \\
\hline Parity & $\begin{array}{l}\text { Nulliparous } \\
(\%) \\
\text { Multiparous } \\
(\%)\end{array}$ & $\begin{array}{l}63 \\
37\end{array}$ & $\begin{array}{l}68 \\
32\end{array}$ & - \\
\hline \multicolumn{2}{|c|}{$\begin{array}{l}\text { Systolic Blood Pressure } \\
\quad(\mathrm{mmHg})\end{array}$} & $160^{*}(140-200)$ & $110(90-112)$ & $\begin{array}{l}114 \\
(100-120)\end{array}$ \\
\hline \multicolumn{2}{|c|}{$\begin{array}{l}\text { Diastolic Blood Pressure } \\
\quad(\mathrm{mmHg})\end{array}$} & $110^{*}(90-120)$ & $69(63-70)$ & $70(65-80)$ \\
\hline \multicolumn{2}{|c|}{ Proteinuria $(\mathrm{mg} / 24 \mathrm{~h})$} & $\begin{array}{l}1510^{\#} \\
(300-18,800)\end{array}$ & $<300$ & ND \\
\hline
\end{tabular}

Values are expressed in percentage or median, with the minimum and maximum values in parentheses. ND = not determined.

$*(\mathrm{p}<0.05)$ vs. normotensive and non-pregnant women (Kruskal-Wallis test).

\# $(\mathrm{p}<0.05)$ vs. normotensive pregnant women (Mann-Whitney $U$ test).

\section{Results}

\subsection{Clinical characteristics}

Analysis of the clinical characteristics of women with PE, normotensive (NT) pregnant women and non-pregnant (NP) women (Table 2) showed no statistical difference in age and race parameters between the groups studied. Similarly, there was no significant difference in gestational age and parity between women with PE and NT pregnant women. Systolic and diastolic blood pressure were significantly higher in the pre-eclamptic group $(\mathrm{p}<0.05)$ than in the NT and NP groups. Additionally, proteinuria concentration was significantly higher $(\mathrm{p}<0.05)$ in women with PE compared to NT pregnant women.

\subsection{Concentration of DAMPs in plasma}

Plasma concentrations of uric acid, Hyaluronan, Hsp70 and HMGB1 were significantly higher in women with PE compared with NT and NP women (Table 3).

\subsection{Basal gene expression and cytokine production by monocytes}

The basal gene expression of NLRP1 (Fig. 1A), NLRP3 (Fig. 1B), caspase-1 (Fig. 1C), IL-1 $\beta$ (Fig. 1D) and TNF- $\alpha$ (Fig. 1E) is significantly increased in monocytes from women with PE when compared to NT and NP groups. HMGB1 (Fig. 1F) and IL-18 (Fig. 1G) showed significantly different expression between pre-eclamptic women and NT women. Lower gene expressions of NLRP1 (Fig. 1A), NLRP3 (Fig. 1B), caspase-1 (Fig. 1C), IL-1 $\beta$ (Fig. 1D) and HMGB1 (Fig. 1F) were detected in the NT group compared to the NP group.

Monocytes from the PE group produced higher levels of IL-1 $\beta$ (Fig. 1H) and TNF- $\alpha$ (Fig. 1I) compared to the NT and NP groups, while IL-18 (Fig. 1J) was elevated only in the PE group compared to the NT group. The production of TNF- $\alpha$ (Fig. 1I) and IL-18 (Fig. 1J) by monocytes from NT women was significantly lower compared to NP group.

3.4. Gene expression and cytokine production by monocytes stimulated with hyaluronan

Stimulation of monocytes with Hyaluronan (HA) led to a significant increase in the gene expression of NLRP1 (Fig. 2A), NLRP3 (Fig. 2B), caspase-1 (Fig. 2C), IL-1 $\beta$ (Fig. 3A) and TNF- $\alpha$ (Fig. 3B) in cells from women with PE compared to the NT and NP groups. Moreover, HMGB1 (Fig. 3D) and IL-18 (Fig. 3E) expression in monocytes stimulated with HA was higher in PE women than in the NT group. It is also possible to notice the lower gene expression of all genes in monocytes stimulated with HA in the NT group compared to the NP group (Figs. 2 and 3). The PE group showed a significant difference between non-stimulated (Co) and HA-stimulated (HA) cells, with an increase in the expression of NLRP3, NLRP1, caspase-1, HMGB1, TNF- $\alpha$, IL-1 $\beta$ and IL-18 by cells stimulated with HA (Figs. 2 and 3).

Figs. 2 and 3 show that treatment of monocytes with $200 \mu \mathrm{M}$ of glibenclamide, an NLRP3 inflammasome inhibitor, led to a decrease in the expression of caspase-1 (Fig. 2D) and IL-1ß (Fig. 3C) by monocytes from NP women, even when these cells were stimulated with HA. These results demonstrated that HA participate in NLRP3 inflammasome activation.

Analysis of cytokine production showed that monocyte stimulation with HA induced higher IL-1 $\beta$ (Fig. 4A) and TNF- $\alpha$ (Fig. 4B) production

Table 3

Concentration of DAMPs in plasma.

\begin{tabular}{|c|c|c|c|}
\hline Parameters & Pregnant women with pre-eclampsia (PE) & Normotensive pregnant women (NT) & Non-pregnant women (NP) \\
\hline Uric acid (mg/dL) & $5.8^{*}(4.5-10.1)$ & $3.8(2.3-4.7)$ & $4.1(2.6-4.8)$ \\
\hline Hyaluronan $(\mathrm{ng} / \mathrm{mL})$ & $135.5^{*}(20.4-296.8)$ & $62.4(2.5-199.7)$ & $42.8(3.3-165.0)$ \\
\hline $\mathrm{Hsp} 70(\mathrm{pg} / \mathrm{mL})$ & $907.1^{*}(404.63-1272.8)$ & $680.23(7.5-1090.4)$ & $655.43(12.7-1083.4)$ \\
\hline HMGB1 (ng/mL) & $8.11^{*}(1.864-97.809)$ & $2.09(1.682-4.789)$ & $2.15(1.848-18.854)$ \\
\hline
\end{tabular}

Values are expressed in median, with the minimum and maximum values in parentheses.

$*(\mathrm{p}<0.05)$ vs. normotensive pregnant women and non-pregnant women (Kruskal-Wallis test). 

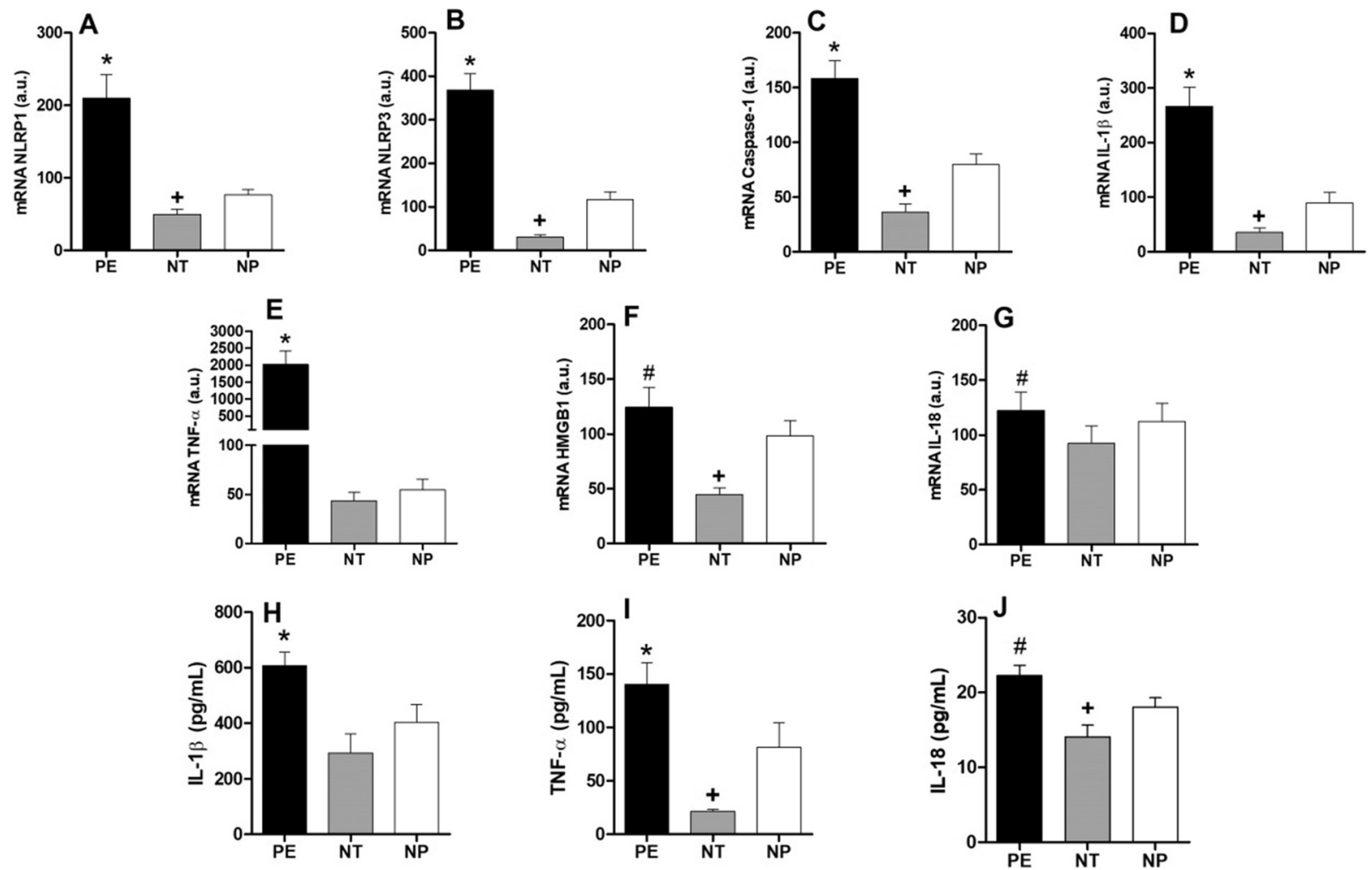

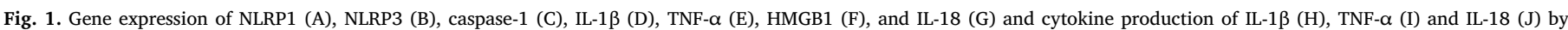

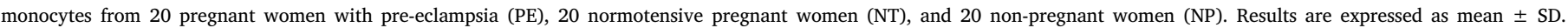
${ }^{*} \mathrm{p}<0.05$ vs. NT and NP; ${ }^{*} \mathrm{p}<0.05$ vs. NT; ${ }^{+} \mathrm{p}<0.05$ vs. NP (ANOVA).
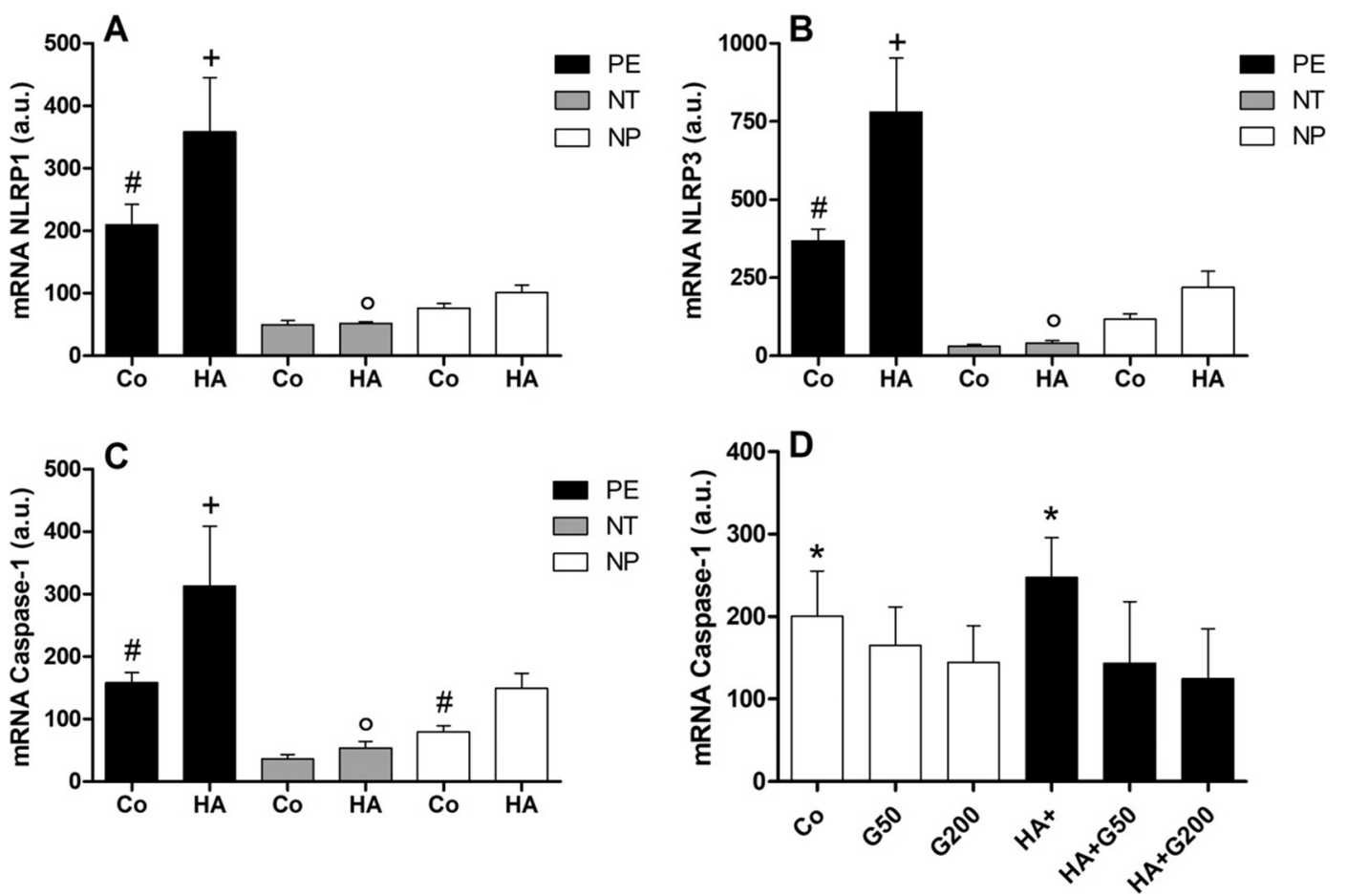

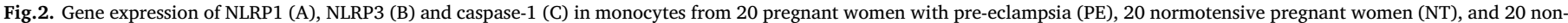

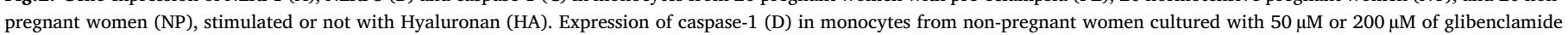
and stimulated or not with HA. Results are expressed as mean \pm SD. ${ }^{+} \mathrm{p}<0.05$ vs. NT and NP; ${ }^{\circ} \mathrm{p}<0.05$ vs. NP; ${ }^{\#}$ p $<0.05$ vs. HA; ${ }^{*} \mathrm{p}<0.05$ vs. G200 (ANOVA).

by the PE group when compared to the NT group. A significant decrease in IL-1 $\beta$ and TNF- $\alpha$ levels produced by HA-stimulated monocytes was observed in the NT group compared to the NP group. When basal (Co) and HA-stimulated monocytes were compared, there was a significant difference in the production of IL-1 $\beta$ (Fig. 4A) in the three groups studied, and in IL-18 levels only in the pre-eclamptic group. However, there was no significant difference between basal and HA-stimulated levels of TNF- $\alpha$ (Fig. 4B) in monocytes from the PE and NT groups. The 

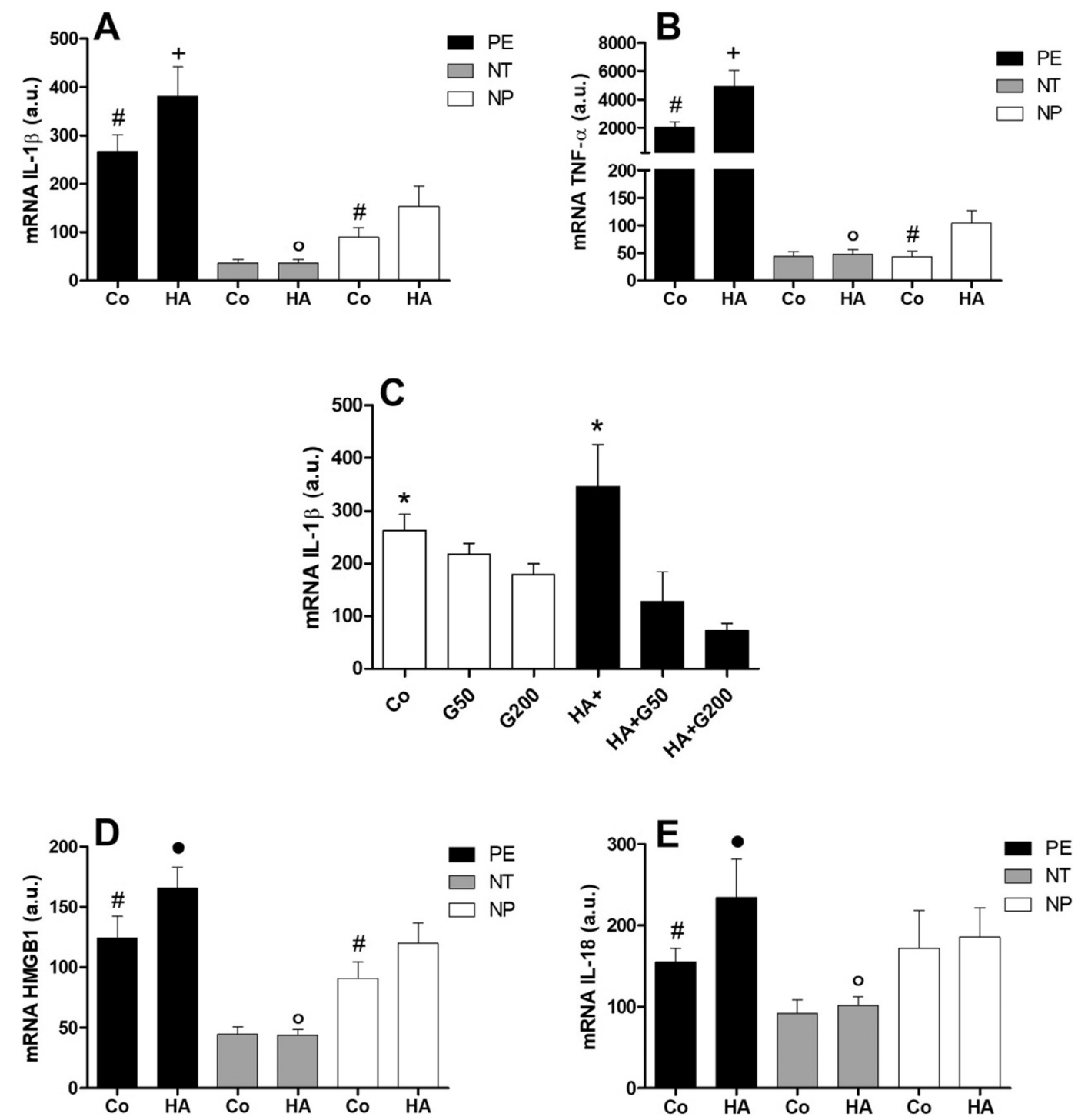

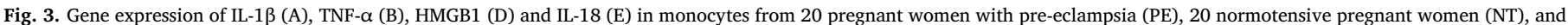

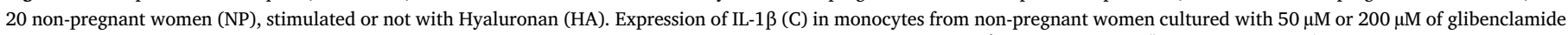

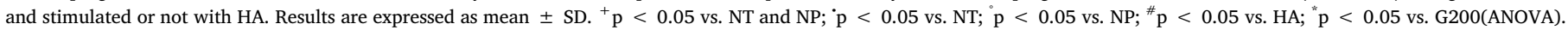

stimulus with HA only induced the higher production of this cytokine in the NP group. No significant production of IL-18 was detected by monocytes stimulated or not with HA in the NT and NP groups (Fig. 4C).

\subsection{Gene expression and cytokine production by monocytes stimulated with Hsp70}

Gene expression of NLRP1 (Fig. 5A), NLRP3 (Fig. 5B), caspase-1 (Fig. 5C), IL-1 $\beta$ (Fig. 5D) and TNF- $\alpha$ (Fig. 5E) by monocytes stimulated with Hsp70 is higher in the group of women with PE compared to the NT and NP groups, while HMGB1 (Fig. 5F) and IL-18 (Fig. 5G) gene expression stimulated with Hsp70 was higher in the PE group only compared to the NT group. Lower expression of NLRP1 (Fig. 5A), NLRP3 (Fig. 5B), caspase-1 (Fig. 5C), IL-1 $\beta$ (Fig. 5D) and HMGB1 (Fig. 5F) genes was observed in monocytes from NT women, stimulated with Hsp70 and compared to the NP group. In the three groups studied, there were no significant differences between unstimulated (Co) and Hsp70-stimulated monocytes in relation to NLRP1, NLRP3, caspase-1, IL-1 $\beta$, HMGB1 and IL-18. Higher gene expression of TNF- $\alpha$ (Fig. 5E) was only observed when monocytes from these three groups were stimulated with Hsp70.
The stimulation of monocytes from NT pregnant women with Hsp70 induced lower IL-1 $\beta$ (Fig. 6A) and TNF- $\alpha$ (Fig. 6B) production compared to the PE and NP groups. In addition, significantly higher differences in these cytokine levels were detected between cultures of monocytes stimulated with Hsp70 and the basal (Co) production by these cells in the three groups studied. No significant difference in relation to IL-18 production after Hsp70 monocyte stimulation was observed when the three groups were compared (Fig. 6C).

\section{Discussion}

The present study evaluated the in vitro involvement of DAMPs, HA and Hsp70 in the inflammatory response detected in PE. The significantly higher plasma concentrations of uric acid, HA, Hsp70 and HMGB1 in women with PE compared with normotensive pregnant women and non-pregnant women confirms studies in the literature showing elevated systemic levels of these DAMPs in pre-eclamptic women and suggest their participation in the pathogenesis of $\mathrm{PE}$ $[12,17,20,25]$. The origin of these DAMPs in plasma is unknown, but there is evidence that they can be released from damaged tissues, stressed or necrotic cells. It is possible that these DAMPs may induce inflammasome hyper activation, resulting in an exaggerated 

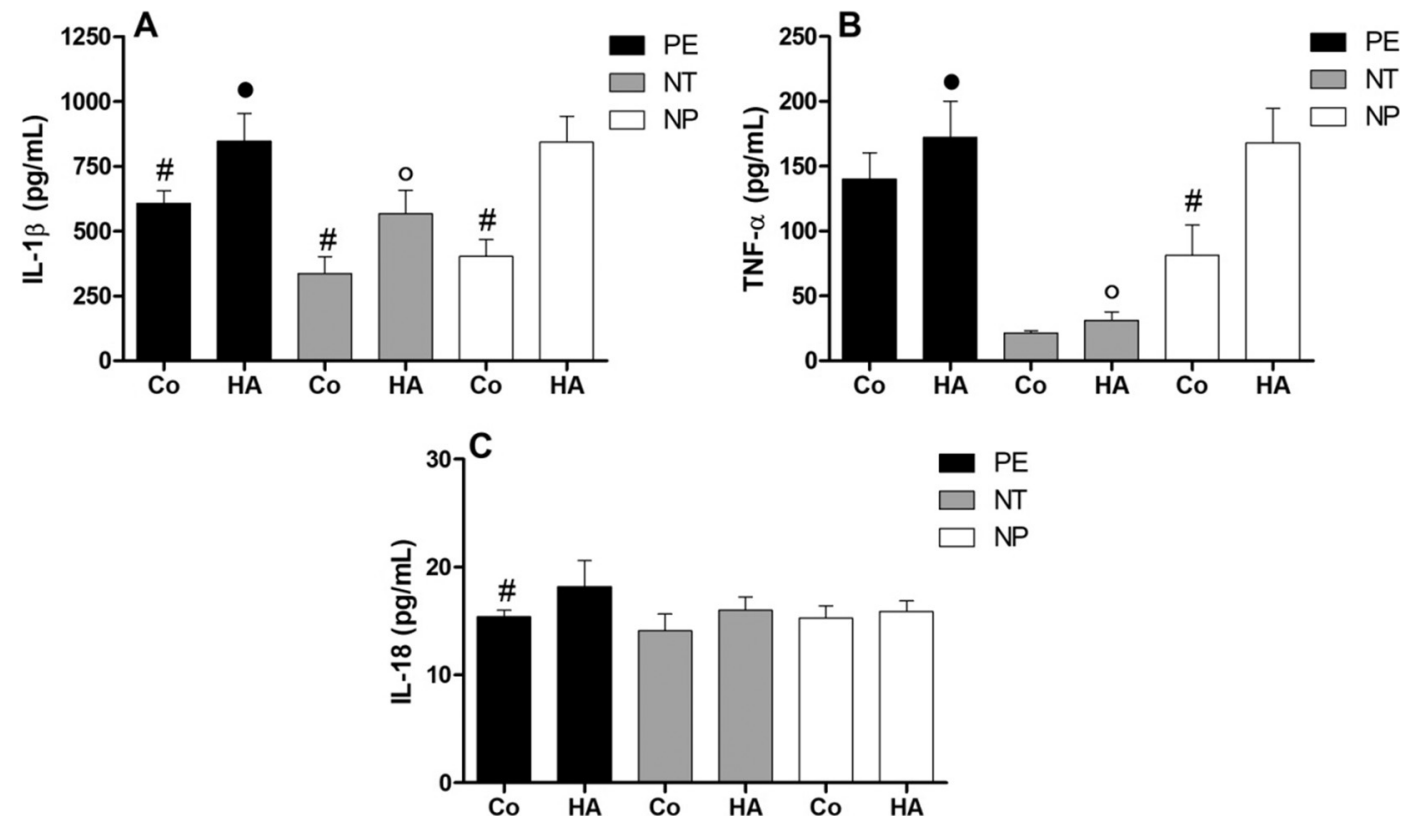

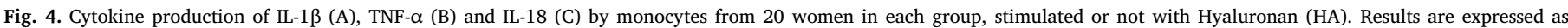
mean \pm SD.

inflammatory state in PE [6].

The spontaneous basal activation of inflammasomes in circulating monocytes of pre-eclamptic women, and the higher plasma levels of uric acid, HA, Hsp70 and HMGB1 detected in these women suggest that monocytes can be activated by alarmins or DAMPs present in the plasma. Analysis of the endogenous gene expression of caspase-1, NLRP1 and NLRP3, as well as IL-1 $\beta$, IL-18, HMGB1 and TNF- $\alpha$ on monocytes of women with PE showed elevated expression, associated with higher protein production of the inflammatory cytokines TNF- $\alpha$ and IL-1 $\beta$, confirming previous results [7].

Monocytes from women with PE stimulated with HA showed higher gene expression of NLRP3 and caspase-1. On the other hand, differently from non-pregnant and normotensive pregnant women, monocytes from pre-eclamptic women had increased NLRP1 expression when stimulated with HA. To our knowledge this is the first study in the literature showing NLRP1 and NLRP3 activation by HA in monocytes from preeclamptic women. This effect may be explained due to an NLRP1 polymorphism variant rs12150220 (L155H) found in women with PE [28], that may allow the bound of HA and NLRP1, enhancing the inflammatory state observed in PE. HA binds to CD44 in murine macrophages after endocytosis and degradation and stimulates NLRP3/ cryopirin system leading to IL-1 $\beta$ production to signal sterile inflammation [29].

The gene expression of HMGB1, IL-1 $\beta$ and TNF- $\alpha$ in monocytes from women with PE and non-pregnant women cultured with HA was elevated when compared to normotensive pregnant women. These results combined with the decreased expression of caspase- 1 and IL-1 $\beta$ in monocytes stimulated with HA plus glybenclamide demonstrated that HA plays a role in inflammasome induction. Moreover when in high plasma concentration HA may be involved in the systemic inflammatory process by maintaining activation of the monocytes from women with PE.

Monocyte stimulation with Hsp70 did not induce a significant increase in NLRP1, NLRP3 and caspase-1 gene expression, suggesting that this DAMP does not directly activate inflammasomes. However, our results showed that the stimulation of monocytes with Hsp70 increase the cytokines production of TNF- $\alpha$ and IL-1 $\beta$. These data indicate that another pathway of activation can be involved in the production of these inflammatory cytokines, probably the TLR4 pathway. Human peripheral blood monocytes, differently from tissue macrophages, have caspase- 1 activated constitutively which is capable to cleave pro-IL- $1 \beta$ in IL-1 $\beta$ biologically active form with only one activation signal, such as the interaction of ligands with TLR2 and TLR4 receptors. Thus, the difference in the regulation of IL-1 $\beta$ production by monocytes and macrophages reflects the different functions of these cells in host defense and inflammation, representing an adaptation of each cell to the environment [30].

The elevated endogenous production of TNF- $\alpha$ by monocytes from pre-eclamptic women detected in the present and in previous studies $[25,31]$ may act in the inflammasome complex as a stimulatory effect on nuclear transcription factor $-\kappa \mathrm{B}(\mathrm{NF}-\kappa \mathrm{B})$. This factor participates in the transcription of genes related to inflammation [32], such as TNF- $\alpha$ and IL-1 $\beta$. On the other hand, these cytokines act by stimulating the activation of NF- $\mathrm{B}$, maintaining a cycle of cellular activation [33]. Although not directly related to the inflammasomes, a recent study demonstrated that in vitro stimulation with TNF- $\alpha$ induces the early expression of NLRP3 mRNA in a 3T3-LI adipocyte line and it is detected after one hour of culture suggesting that NLRP3 gene expression is immediately responsive to TNF- $\alpha$ [34].

The stimulation response of monocytes from normotensive pregnant women cultured with HA and Hsp70 were different from the response of monocytes from pre-eclamptic and non-pregnant women, showing diminished expression of the inflammatory cytokines IL-1 $\beta$, IL-18, TNF$\alpha$ and HMGB1. This lower expression observed in normotensive pregnant group could be due to the regulation exerted by IL-10 in these cells. The anti-inflammatory cytokine predominance in normal pregnancy could regulate the inflammatory response that occurs during pregnancy by controlling the gene expression of IL-1 $\beta$ and TNF- $\alpha$ [35].

\section{Conclusion}

The present study demonstrated that monocytes from pre-eclamptic women show endogenous activation of NLRP1 and NLRP3 inflammasomes, and express elevated levels of TNF- $\alpha$, IL-1 $\beta$, IL-18 and HMGB1. The activation of these inflammasomes was associated with the higher plasma concentration of HA in these pregnant women. The stimulation of monocytes with HA induced increased gene expression of NLRP1, NLRP3, caspase-1, IL-1 $\beta$, TNF- $\alpha$, HMGB1 and IL-18, with the production of IL-1 $\beta$ being more evident in pre-eclamptic and non-pregnant women. Monocytes stimulated with Hsp70 contributed to IL-1 $\beta$ and 
A

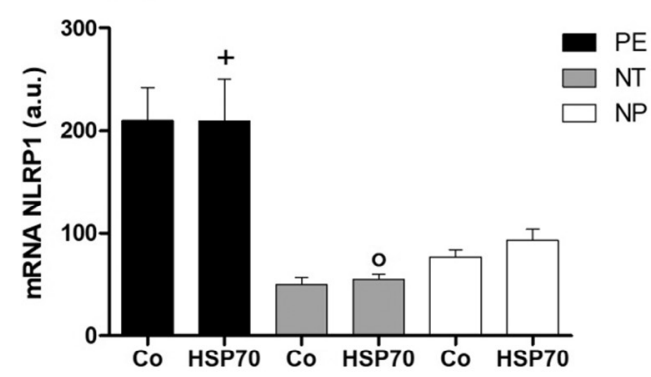

B

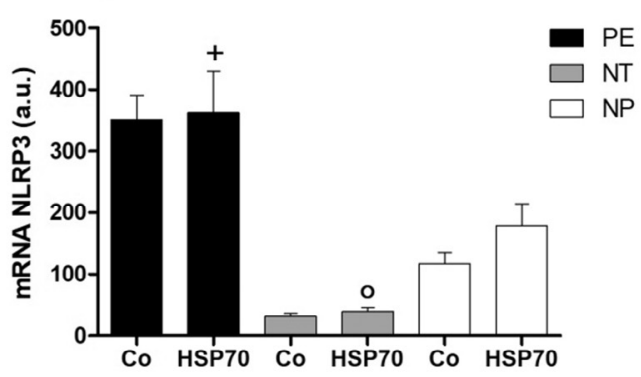

C

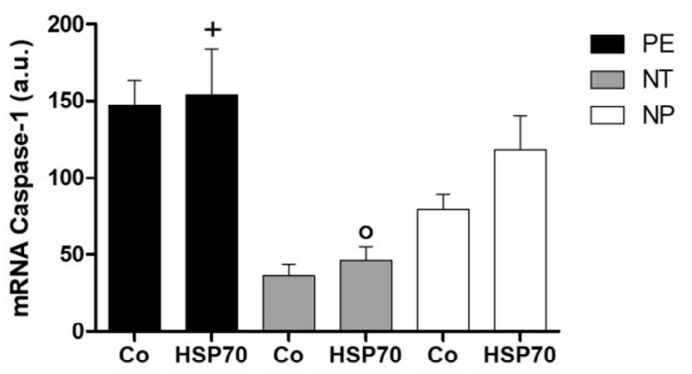

D

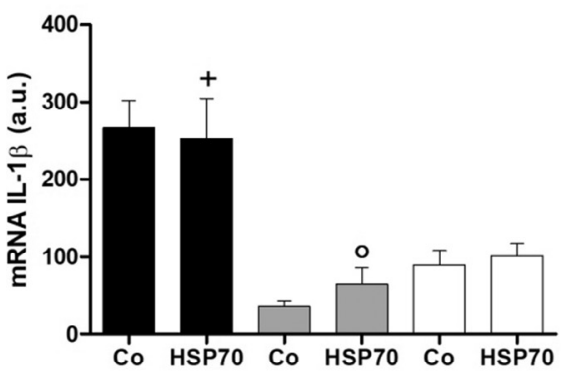

$\mathbf{F}$

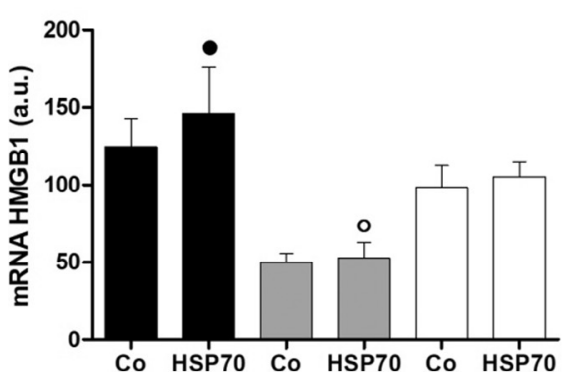

E

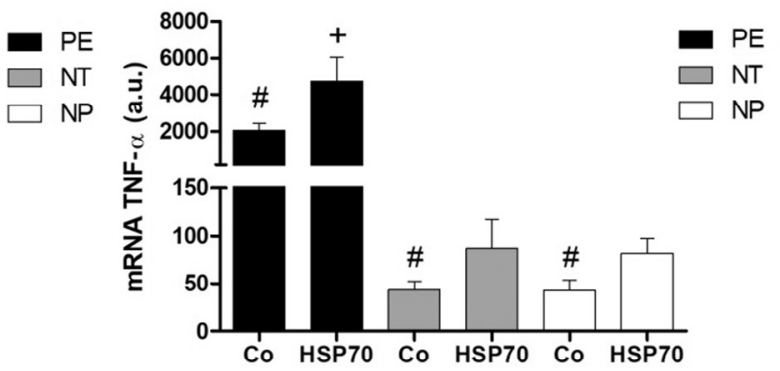

G
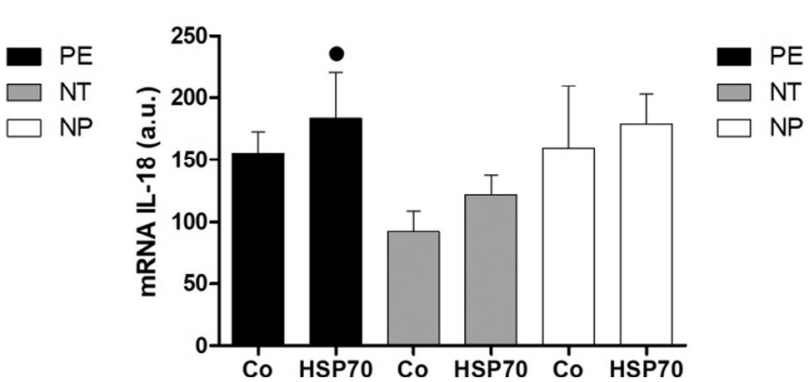

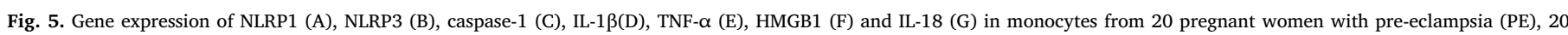

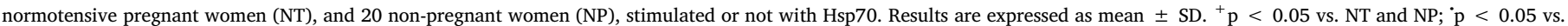
NT; ${ }^{\circ}<0.05$ vs. NP; ${ }^{\#} \mathrm{p}<0.05$ vs. Hsp70 (ANOVA).

TNF- $\alpha$ production by these cells through a mechanism that is independent of inflammasome activation. These results suggest the participation of these DAMPs in the systemic inflammatory response characteristic of PE. The study of mechanisms involved in the activation of monocytes by DAMPs in women with PE, whether or not dependent on inflammasomes, will allow a better understanding of this important inflammatory syndrome of pregnancy.

\section{Acknowledgements}

This work was supported by the Fundação do Amparo à Pesquisa do
Estado de São Paulo, Brazil, FAPESP, (Grant Nos. 2012/24697-8 and 2013/00534-5). The authors thank the staff of the hospitals and the women who participated in this study.

\section{Author contributions}

MRV, MLM, VRR and PRN performed experiments. VTB and JCP selected pregnant women for the study. MRV and MTSP conceived the ideas, designed experiments, analyzed data and prepared the manuscript. 

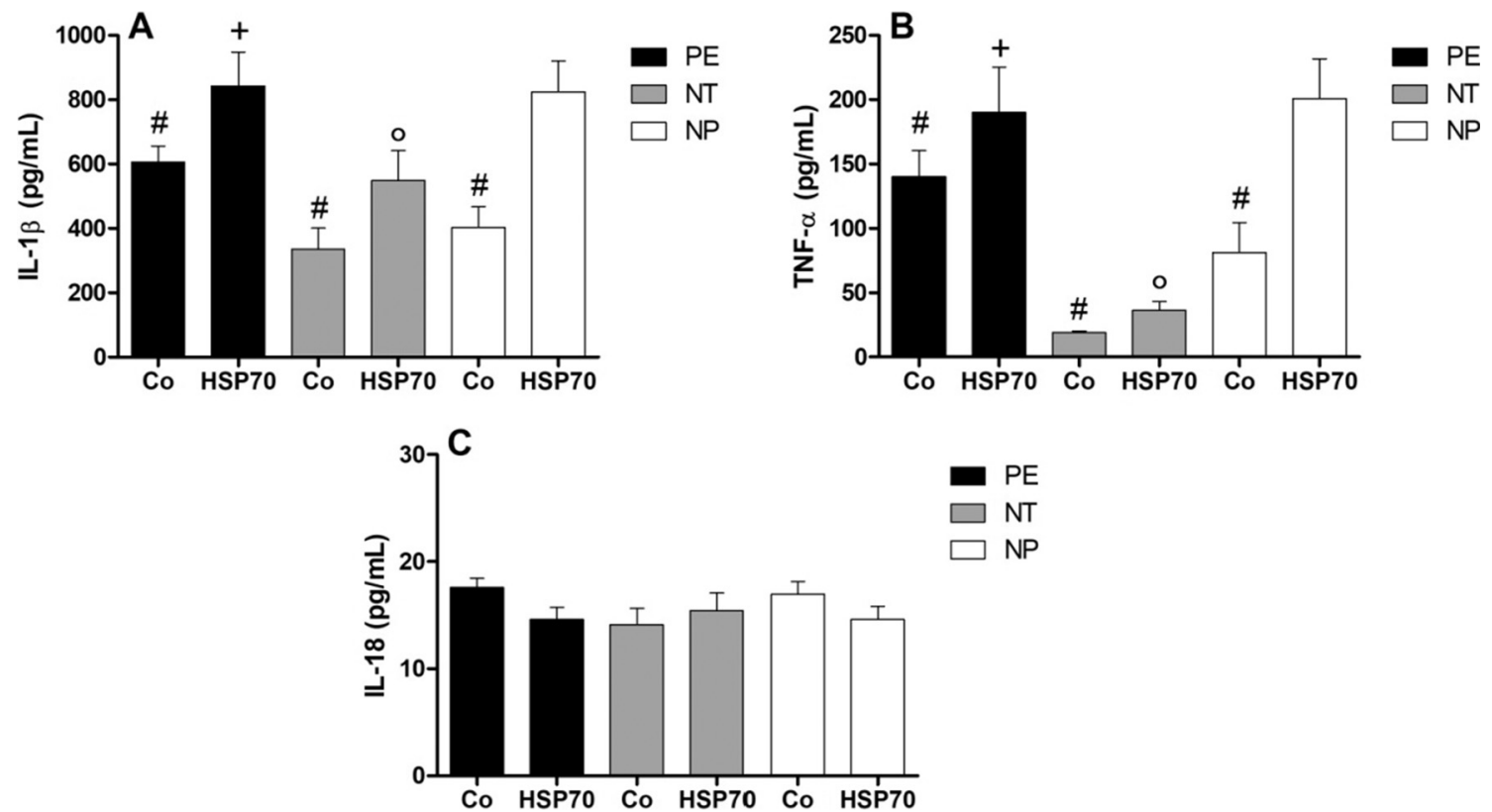

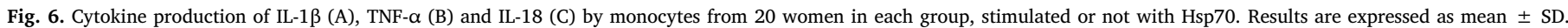
${ }^{+} \mathrm{p}<0.05$ vs. NT and NP; $\mathrm{p}<0.05$ vs. NT; ${ }^{\circ} \mathrm{p}<0.05$ vs. NP; ${ }^{\#} \mathrm{p}<0.05$ vs. Hsp70 (ANOVA).

\section{Disclosure}

The authors declare no conflict of interest.

\section{References}

[1] B.B. van Rijn, A. Franx, E.A. Steegers, C.J. de Groot, R.M. Bertina, G. Pasterkamp, H.A. Voorbij, H.W. Bruinse, M. Roest, Maternal TLR4 and NOD2 gene variants, proinflammatory phenotype and susceptibility to early-onset preeclampsia and HELLP syndrome, PLoS One 3 (4) (2008) e1865.

[2] ACOG Practice Bulletin no. 33, Diagnosis and management of preeclampsia and eclampsia, Obstet. Gynecol. 99 (2002) 159-167.

[3] National High Blood Pressure Education Program Working Group on High Blood Pressure in Pregnancy, Report of National High Blood Pressure Education Program Working Group on High Blood Pressure in Pregnancy, Am. J. Obstet. Gynecol. 183 (1) (2000) 1-22.

[4] A.L. Tranquilli, G. Dekker, L. Magee, J. Roberts, B.M. Sibai, W. Steyn, G.G. Zeeman, M.A. Brown, The classification, diagnosis and management of the hypertensive disorders of pregnancy: a revised statement from the ISSHP, Pregnancy Hypertens 4 (2) (2014) 97-104.

[5] B.W. Mol, C.T. Roberts, S. Thangaratinam, L.A. Magee, C.J. de Groot, G.J. Hofmeyr, Pre-eclampsia. Lancet 387 (10022) (2016) 999-1011.

[6] R.N. Khan, D.P. Hay, A clear and present danger: inflammasomes DAMPing down disorders of pregnancy, Hum. Reprod. Update. 21 (3) (2015) 388-405.

[7] M.L. Matias, M. Romão, I.C. Weel, V.R. Ribeiro, P.R. Nunes, V.T. Borges, et al., Endogenous and uric acid-induced activation of NLRP3 inflammasome in pregnant women with preeclampsia, PLoS One 10 (6) (2015) e0129095.

[8] P. Mandrekar, D. Catalano, V. Jeliazkova, K. Kodys, Alcohol exposure regulates heat shock transcription factor binding and heat shock proteins 70 and 90 in monocytes and macrophages: implication for TNF-alpha regulation, J. Leukoc. Biol. 84 (5) (2008) 1335-1345.

[9] J.S. Park, D. Svetkauskaite, Q. He, J.Y. Kim, D. Strassheim, A. Ishizaka, E. Abraham, Involvement of toll-like receptors 2 and 4 in cellular activation by high mobility group box 1 protein, J. Biol. Chem. 279 (9) (2004) 7370-7377.

[10] G.M. Campo, A. Avenoso, S. Campo, A. D'Ascola, G. Nastasi, A. Calatroni, Small hyaluronan oligosaccharides induce inflammation by engaging both toll-like-4 and CD44 receptors in human chondrocytes, Biochem. Pharmacol. 80 (4) (2010) 480-490.

[11] N. Saïd-Sadier, D.M. Ojcius, Alarmins, inflammasomes and immunity, Biomed. J. 35 (6) (2012) 437-449.

[12] J.C. Peraçoli, C.F. Bannwart-Castro, M. Romao, I.C. Weel, V.R. Ribeiro, V.T. Borges, et al., High levels of heat shock protein 70 are associated with proinflammatory cytokines and may differentiate early- from late-onset preeclampsia, J. Reprod. Immunol. 100 (2) (2013) 129-134.

[13] K.H. Lee, J. Jeong, C.G. Yoo, Positive feedback regulation of heat shock protein 70 (Hsp70) is mediated through Toll-like receptor 4-PI3K/Akt-glycogen synthase kinase-3ß pathway, Exp. Cell. Res. 319 (1) (2015) 88-95.

[14] Q. Chen, Y.X. Yin, J. Wei, M. Tong, F. Shen, M. Zhao, L. Chamley, Increased expression of high mobility group box 1 (HMGB1) in the cytoplasm of placental syncytiotrophoblast from preeclamptic placentae, Cytokine. 85 (2016) 30-36.
[15] M. Lamkanfi, A. Sarkar, L. VandeWalle, A.C. Vitari, A.O. Amer, M.D. Wewers, K.J. Tracey, T.D. Kanneganti, V.M. Dixit, Inflammasome-dependent release of the alarmin HMGB1 in endotoxemia, J. Immunol. 185 (7) (2010) 4385-4392.

[16] K. Naruse, T. Sado, T. Noguchi, T. Tsunemi, S. Yoshida, J. Akasaka, et al., Peripheral RAGE (receptor for advance glycation endproducts)-ligands in normal pregnancy and preeclampsia: novel markers of inflammatory response, J. Reprod. Immunol. 93 (2) (2012) 69-74.

[17] L. Zhu, Z. Zhang, L. Zhang, Y. Shi, J. Qi, A. Chang, J. Gao, Y. Feng, X. Yang, HMGB1RAGE signaling pathway in severe preeclampsia, Placenta. 36 (10) (2015) 1148-1152.

[18] K. Yamasaki, J. Muto, K.R. Taylor, A.L. Cogen, D. Audish, J. Bertin, E.P. Grant, A.J. Coyle, A. Misaghi, H.M. Hoffman, R.L. Gallo, NLRP3/cryopyrin is necessary for interleukin-1 $\beta$ (IL-1 $\beta$ ) release in response to hyaluronan, an endogenous trigger of inflammation in response to injury, J. Biol. Chem. 284 (19) (2009) 12762-12771.

[19] S. Berg, A. Engman, S. Holmgren, T. Lundahl, T.C. Laurent, Increased plasma hyaluronan in severe pre-eclampsia and eclampsia, Scand. J. Clin. Lab. Invest. 61 (2) (2001) 131-137.

[20] M. Romão, I.C. Weel, S.J. Lifshitz, M.T. Peracoli, S. Witkin, Elevated hyaluronan and extracellular matrix metalloproteinase inducer levels in women with preeclampsia, Arch. Gynecol. Obstet. 289 (3) (2014) 575-579.

[21] Y.M. Kim, R. Romero, S.Y. Oh, C.J. Kim, B.A. Kilburn, D.R. Armant, J.K. Nien, R. Gomez, M. Mazor, S. Saito, V.M. Abrahams, G. Mor, Toll-like receptor 4: a potential link between "danger signals," the innate immune system, and preeclampsia? Am. J. Obstet. Gynecol. 193 (3 Pt 2) (2005) 921-927.

[22] B.K. Davis, H. Wen, J.P. Ting, The inflammasome NLRs in immunity, inflamation, and associated diseases, Annu. Rev. Immunol. 29 (2011) 707-735.

[23] T. Strowig, J. Henao-Mejia, E. Elinav, R. Flavell, Inflammasomes in health and disease, Nature 481 (7381) (2012) 278-286.

[24] L. Franchi, T. Eigenbrod, R. Muñoz-Planillo, G. Nuñez, The inflammasome: a caspase-1-activation platform that regulates immune responses and disease pathogenesis, Nat. Immunol. 10 (3) (2009) 241-247.

[25] M.T. Peraçoli, C.F. Bannwart, R. Cristofalo, V.T. Borges, R.A. Costa, S.S. Witkin, et al., Increased reactive oxygen species and tumor necrosis factor-alpha production by monocytes are associated with elevated levels of uric acid in preeclamptic women, Am. J. Reprod. Immunol. 66 (6) (2011) 460-467.

[26] C.Y. Li, K.W. Lam, L.T. Yam, Esterases in human leukocytes, J. Histochem. Cytochem. 21 (1) (1973) 1-12.

[27] A. Larionov, A. Krause, W. Miller, A standard curve based method for relative real time PCR data processing, BMC Bioinform. 6 (2005) 62.

[28] A. Pontillo, E.C. Reis, P.N. Bricher, P. Vianna, S. Diniz, K.S. Fernandes, J.A. Chies, V. Sandrim, NLRP1 L155H polymorphism is a risk factor for preeclampsia development, Am. J. Reprod. Immunol. 73 (6) (2015) 577-581.

[29] K. Yamasaki, J. Muto, K.R. Taylor, A.L. Cogen, D. Audish, J. Bertin, E.P. Grant, A.J. Coyle, A. Misaghi, H.M. Hoffman, R.L. Gallo, NLRP3/cryopyrin is necessary for interleukin-1beta (IL-1beta) release in response to hyaluronan, an endogenous trigger of inflammation in response to injury, J Biol Chem. 284 (19) (2009 May 8) 12762-12771.

[30] M.G. Netea, C.A. Nold-Petry, M.F. Nold, L.A. Joosten, B. Opitz, J.H. van der Meer, F.L. van de Veerdonk, G. Ferwerda, B. Heinhuis, I. Devesa, C.J. Funk, R.J. Mason, B.J. Kullberg, A. Rubartelli, J.W. van der Meer, C.A. Dinarello, Differential requirement for the activation of the inflammasome for processing and release of IL1beta in monocytes and macrophages, Blood 113 (10) (2009) 2324-2335. 
[31] R. Cristofalo, C.F. Bannwart-Castro, C.G. Magalhães, V.T. Borges, J.C. Peraçoli, S.S. Witkin, et al., Silibinin attenuates oxidative metabolism and cytokine produc tion by monocytes from preeclamptic women, Free Radic. Res. 47 (4) (2013) 268-275.

[32] I. Striz, E. Brabcova, L. Kolesar, X.D. Liu, I. Brabcova, A. Sekerkova, J.A. Poole, M. Jaresova, A. Slavcev, S.I. Rennard, Epithelial cells modulate genes associated with NF kappa B activation in co-cultured human macrophages, Immunobiology 216 (10) (2011) 1110-1116.
[33] S. Vallabhapurapu, M. Karin, Regulation and function of NF-kappaB transcription factors in the immune system, Annu. Rev. Immunol. 27 (2009) 693-733.

[34] M. Furuoka, K.I. Ozaki, D. Sadatomi, S. Mamiya, T. Yonezawa, S. Tanimura, K. Takeda, TNF- $\alpha$ induces caspase-1 activation independently of simultaneously induced NLRP3 in 3T3-L1 cells, J. Cell. Physiol. 231 (12) (2016) 2761-2767.

[35] K.W. Moore, R. de Waal Malefyt, R.L. Coffman, A. O'Garra, Interleukin-10 and the interleukin-10 receptor, Annu. Rev. Immunol. 19 (2001) 683-765. 